\title{
Regret and Behavior: Comment on Zeelenberg and Pieters
}

\author{
Neal J. Roese, Amy Summerville, and Florian Fessel \\ University of Illinois
}

\begin{abstract}
Zeelenberg and Pieter's (2007) regret regulation theory 1.0 offers a synthesis that brings together concepts spanning numerous literatures. We have no substantive disagreement with their theory, but instead offer 3 observations to further aid regret researchers studying consumer decision making. First, the overall arch of any regret theory must be situated within an understanding of behavior regulation. Second, the distinction between regrets of action versus inaction is best understood in terms of motivational implications, particularly with regard to Higgin's (1998) distinction between promotion and prevention focus. Third, the opportunity principle offers a particularly clear means of summarizing the regulatory consequences of the regret experience. Regret is an emotion pivotal for decision making, and its cognitive underpinning has and continues to be elucidated in research focusing on counterfactual thinking.
\end{abstract}

In their regret regulation theory 1.0, Zeelenberg and Pieters (2007) offer a theoretical synthesis that brings together a range of concepts and findings spanning numerous literatures, all centering in one way or another on the construct of regret. Intriguingly, they label their theory version 1.0, thus acknowledging exciting prospects for future revision in light of the fervent research attention that the concept of regret continues to garner. Computer software is routinely labeled with such numbers, with whole versus decimal numbers signifying larger versus smaller revisions. The earliest hacker spirit of the 1960s emphasized a communal spirit, in which software code written (on paper!) on one particular day would be left in a file drawer for another programmer to improve upon the next day, a vivid embodiment of the core values of science itself (Levy, 2001). We hope that the ideas and suggestions contained in the present commentary are accepted in a similar collaboratory spirit.

Zeelenberg and Pieters (2007) explicitly frame their theory as an integration of previously understood principles. They have done an admirable job of bringing together many diverse observations, and we applaud rather than dispute their main conclusions. Nevertheless, their synthesis involves substantial subjective interpretation, necessitated by the embryonic state of the literature. In the remainder of this commentary, we emphasize three theoretical points that

Correspondence should be addressed to Neal Roese, Department of Psychology, University of Illinois, Champaign, IL 61820, USA, E-mail: roese@uiuc.edu our own subjective interpretation deems essential to an understanding of regret in its consumer decision-making context.

\section{BEHAVIOR REGULATION VERSUS REGRET REGULATION}

People regulate their regrets, as they regulate all of their emotions. True though this may be, to focus on regret regulation is to miss the larger theoretical picture. Regret regulation is secondary to behavior regulation, which refers to the ongoing management of effective daily behavior. Emotion is merely a signal, one of many inputs into the regulatory loop governing single and sequential actions that together ensure survival and success (Roese, Sanna, \& Galinsky, 2005; Roese \& Sherman, in press). Consumers are certainly motivated to avoid regret, but this is simply a byproduct of their more basic desire to avoid bad products and poor service. Consumers reverse their prior decisions not to eliminate regret so much as to attain better outcomes. People regulate regret in order to regulate behavior.

Does this render the title of Zeelenberg and Pieter's (2007) theory a misnomer? Not entirely. Like any negative emotional state, individuals are motivated to reduce regret, and this observation explains a wide range of findings. Yet placing this observation within the larger perspective of behavior regulation clarifies broader patterns which may be especially useful to researchers in consumer decision making. Our next two comments exemplify this prospect. 


\section{MOTIVATIONAL IMPLICATIONS OF THE ACTION-INACTION DISTINCTION: REGULATORY FOCUS}

To do or not to do, that is the question of Zeelenberg and Pieter's (2007) Proposition 7. Much research has examined the distinction between regrets of action versus inaction. In a nutshell, people may kick themselves for doing something (buying stock in Enron just before it tanked) or not doing something (missing out on buying stock in Google before it took off). The earliest research asked the question of which kind of regret predominates (answer: it depends); later research specified moderator variables (e.g., temporal perspective, decision justifiability). Such research assumes that the functional consequences (i.e., processes of subsequent regulatory activity) are equivalent for regrets of action versus action, hence the question is simply which combination of situational variables serve to intensify regret per se.

Importantly, however, these two kinds of regret do appear to differ qualitatively in terms of their motivational implications. Regrets of action tend to center on avoidance, whereas regrets of inaction tend to center on approach. This connection may be phrased in terms of Higgin's (1998) theory of regulatory focus, which has recently been applied fruitfully to diverse topics in consumer psychology (e.g., Dholakia, Gopinath, Bagozzi, \& Nataraajan, in press; Jain, Agrawal, \& Maheswaran, in press; Keller, in press). In these terms, we may differentiate between promotion failure (e.g., not being able to attain a desired product or situation) versus prevention failure (e.g., not being able to bypass a undesirable product or situation). Lee and Aaker (2004) showed that advertising is more persuasive if it is framed so as to match the situationally varying regulatory focus of the perceiver. Advertising keyed to "acquiring great looks and exceptional engineering" is more effective when the audience is in a promotion focus, whereas advertising that emphasizes "getting stranded by not having the emergency road and safety kit" (p. 205) is more effective when the audience is in a prevention focus.

Regrets of inaction are more likely to be activated when the individual has suffered a promotion failure, but regrets of action are more likely when the individual has suffered a prevention failure (Pennington \& Roese, 2003a; Roese, Hur, \& Pennington, 1999; Roese et al., 2006). In large part this pattern stems from a simple matching of normative expectancies. People tend to see positive outcomes as a result of their deliberate acts, hence failing to reach a desired positive state creates a regret focusing on specific acts or decisions that should have been taken to have achieved that positive state. By contrast, people tend to look at an accident (or other prevention failures) in terms of avoiding them by deleting an inappropriate decision or action. Promotion and prevention focus may themselves elicit regrets of inaction and action, respectively. Moreover, a focus on the distant (as opposed to recent) past or future tends to involve both an emphasis not only on regrets of inaction (as opposed to action), but also on promotion failures or promotion goals in general (as opposed to prevention goals; Pennington \& Roese, 2003b; see also Burrus \& Roese, in press).

That the action-inaction regret distinction holds distinct motivational implications opens many doors to new research in consumer psychology. Two possibilities seem evident. First, knowing that consumers are sometimes dissatisfied, advertising might be framed in terms of promotion or prevention concerns so as to match, and assuage, the predominant form of regret involved with the particular product in question. Second, advertising might actually emphasize regret of either action or inaction, then recommend specific actions geared to either eagerness (i.e., promotion) or vigilance (i.e., prevention).

\section{FROM REGRET TO BEHAVIOR: THE OPPORTUNITY PRINCIPLE}

What comes of regret? Under Proposition 10, Zeelenberg and Pieters (2007) argue that the consequences of regret fall into three main categories, centering on decision, alternatives, or feelings. These categories are certainly sensible in that they capture the variation in content of past research efforts. But they do little to suggest any higher order principle that systematizes distinct functional principles. We suggest that another distinction, itself borrowed from prior theory, does a better job of illuminating the consequences not only of regret but of any negative emotional experience. It will be obvious that this recommendation is a further instantiation of the idea that behavior regulation, and not regret or emotion regulation per se, is the primary regulatory enterprise of human brains.

When people experience threat, either physical or psychological, they can respond in two different ways (Roese \& Olson, in press). One is behavioral: The individual directly acts on the threat to reduce or avoid it (e.g., runs away from a predator; reverses a questionable decision; searches for a new romantic partner). The other is cognitive: The individual mentally reconstrues the circumstances so as to put it in a better light (e.g., deflects blame from the self; derogates a rejected option; thinks optimistically about the future). These two categories have been distinguished in a variety of literatures; for example, stress researchers labeled them problem-focused coping versus emotionfocused coping (e.g., Lazarus \& Folkman, 1984); in the literature on attitudinal responses to threatening persuasive appeals, they have been labeled danger-control and fearcontrol (e.g., Leventhal, 1970). Gilbert and Ebert (2002) suggested a temporal ordering, such that behavioral remediation is the default: "When suboptimal outcomes threaten a person's satisfaction, the first line of defense is to change the outcome, and it is only when such efforts 
prove futile that ... the person's subjective experience [is actively modified]" (p. 504).

Within Zeelenberg and Pieter's (2007) list of regret consequences, only one is behavioral: undo or reverse decision. We argue that this is the primary, pivotal, and default response. Buy a different product next time. Educate yourself about product lines and feature options. Expose your mind to more (or less!) information relevant to the decision. Don't go to that restaurant anymore. The behavioral response is about acting to improve the current circumstance in an ongoing manner. We argue that regret serves primarily as a motivational kick toward further action and future betterment, one that is largely implicit, or hidden from conscious recognition (Roese, 2005). All the remaining regret consequences outlined by Zeelenberg and Pietersjustify decision, deny responsibility, reappraise alternatives, psychological repair work, and regret suppression-are simply instances of cognitive reconstrual. In a different era, all would have been bundled under the heading of cognitive dissonance reduction.

When is the behavioral versus cognitive response more likely? The opportunity principle (Roese \& Summerville, 2005) describes the surprising notion that regrets are more intense when opportunities exist for further action, or more specifically, for further rectification of current problems. Where opportunity is denied, or where problematic circumstances are inevitable, cognitive reconstrual (dissonance reduction) is activated to minimize the regret experience (i.e., to make the individual feel better). Accordingly, regret persists in precisely those situations in which opportunity for positive action remains high. Consistent with our main point that regret regulation subserves behavior regulation, regret itself spurs further corrective action. Regret motivates people toward revised decision making and corrective action that often bring improvement in life circumstances (Nasco \& March, 1999; Roese, 1997, 1999; Zeelenberg \& Pieters, 1999).

Roese and Summerville (2005) were the first to stitch together the diverse strands of previous work that had supported the opportunity principle, yet which had never before been glimpsed as part of the same underlying concept (see pp. 1274-1275). Some of that prior research centered on regret specifically, some on counterfactual thinking, and some on disappointment or negative affect more generally. This principle helps to settle a huge question: When does regret occur? Regret theorists want to believe that regret is an inevitable consequence of the act of deciding, yet the cognitive dissonance tradition suggested that regret is often absent, because it is has been actively quashed. More recent research shows that the positive aspects of the chosen option are better remembered than the negative aspects, with the reverse characterizing unchosen options (Mather, Shafir, \& Johnson, 2000, 2003). Roese and Summerville argued that the opportunity principle helps finally to reconcile regret theory with dissonance theory, by pointing out the circumstances under which each prevails.

\section{CODA: REGRET OR COUNTERFACTUAL?}

Zeelenberg and Pieters (2007) echoed previous theorists in defining regret as a counterfactual emotion. We conclude by noting the false division between regret and counterfactual, as constructs but also as literatures. Some theorists believe that these terms reference affect and cognition, respectively, but in an important essay, Sabini and Silver (2005) pointed out the inherent ambiguity in theorizing on the basis of self-reports rooted to lay emotion. If regret is defined for research subjects during an experiment, this definition cannot but look very much like the definition of upward, self-focused counterfactual thinking (e.g., "to what extent do you wish that your decision had been different so that you could have obtained a better outcome?"). If both regret and counterfactual are measured via the lens of verbal self-report, their operational distinction is necessarily and unavoidably blurred.

We raise this point only because several of our own theoretical observations derived from a balanced appraisal of research reports with titles mentioning both regret as well as counterfactual thinking. The primacy of behavior regulation, for example, was recognized in earlier theory on the functional basis of counterfactual thinking (Roese, 1994, 1999, 2000, 2005; Roese \& Olson, 1997; Roese et al., 2005). Regulatory focus theory was initially connected to counterfactuals (Roese et al., 1999), but subsequent research used self-reports in which "regret" was explicitly named to subjects, with precisely the same result (Roese et al., 2006, Study 2). Finally, the initial glimmer of the opportunity principle appeared in a study of counterfactual thoughts evoked by gambling outcomes (Markman, Gavanski, Sherman, \& McMullen, 1993), yet the same principle was evident in studies of action-inaction regrets (Gilovich \& Medvec, 1994), and in a new experiment that focused on participants' biggest regrets in life (Roese \& Summerville, 2005 , Study 2b). As such, we urge researchers studying regret in consumer contexts to consult the published literature with searches using both regret and counterfactual as separate keywords (Roese, 2000).

To conclude, Zeelenberg and Pieters (2007) have done the study of consumer decision making an enormous service by pulling together diverse conceptual strands into their regret regulation theory version 1.0. They have done a remarkable job and we have no substantive quibbles with their interpretation of the meaning of past findings. We do believe, however, that the overall arc of any regret theory must be situated within an understanding of behavior regulation. Regret, like all emotion, is a regulatory signal feeding into the management of effective ongoing behavior. 


\section{ACKNOWLEDGMENTS}

Order of authorship for the second and third authors was determined with a coin toss. Preparation of this paper was supported by National Institute of Mental Health grant R01MH055578.

\section{REFERENCES}

Burrus, J., \& Roese, N. J. (2006). Long ago it was meant to be: The interplay between time, construal and fate beliefs. Personality and Social Psychology Bulletin, 32, 1050-1058.

Dholakia, U. M., Gopinath, M., Bagozzi, R. P., \& Nataraajan, R. (2006). The role of regulatory focus in the experience and self-control of desire for temptations. Journals of Consumer Psychology, 16, $163-175$.

Gilbert, D. T., \& Ebert, J. E. J. (2002). Decisions and revisions: The affective forecasting of changeable outcomes. Journal of Personality and Social Psychology, 82, 503-514.

Gilovich, T., \& Medvec, V. H. (1994). The temporal pattern to the experience of regret. Journal of Personality and Social Psychology, 67, 357-365.

Higgins, E. T. (1998). Promotion and prevention: Regulatory focus as a motivational principle. In M. P. Zanna (Ed.), Advances in experimental social psychology (Vol. 30, pp. 1-46). San Diego, CA: Academic Press.

Jain, S. P., Agrawal, N., \& Maheswaran, D. (2006). When more may be less: The effects of regulatory focus on responses to different comparative frames. Journal of Consumer Research, 33, 91-98.

Keller, P. A. (2006). Regulatory focus and efficacy of health messages. Journal of Consumer Research, 33, 109-114.

Lazarus, R. S., \& Folkman, S. (1984). Stress, appraisal, and coping. New York: Springer-Verlag.

Lee, A., \& Aaker, J. (2004). Bringing the frame into focus: The influence of regulatory fit on processing fluency and persuasion. Journal of Personality and Social Psychology, 86, 205-218.

Leventhal, H. (1970). Findings and theory in the study of fear communications. In L. Berkowitz (Ed.), Advances in experimental social psychology (Vol. 5, pp. 119-186). New York: Academic Press.

Levy, S. (2001). Hackers: Heroes of the computer revolution. New York: Penguin.

Markman, K. D., Gavanski, I., Sherman, S. J., \& McMullen, M. N. (1993). The mental simulation of better and worse possible worlds. Journal of Experimental Social Psychology, 29, 87-109.

Mather, M., Shafir, E., \& Johnson, M. K. (2003). Remembering chosen and assigned options. Memory and Cognition, 31, 422-433.
Nasco, S. A., \& Marsh, K. L. (1999). Gaining control through counterfactual thinking. Personality and Social Psychology Bulletin, 25, 556-568.

Pennington, G. L., \& Roese, N. J. (2003a). Counterfactual thinking and regulatory focus. In Spencer, S. J., Fein, S., Zanna, M. P., \& Olson, J. M. (Eds.). Motivated social perception: The Ontario Symposium (Vol 9, pp. 277-298). Mahwah, NJ: Lawrence Erlbaum Associates, Inc.

Pennington, G. L., \& Roese, N. J. (2003b). Regulatory focus and temporal perspective. Journal of Experimental Social Psychology, 39, 563-576.

Roese, N. J. (1994). The functional basis of counterfactual thinking. Journal of Personality and Social Psychology, 66, 805-818.

Roese, N. J. (1997). Counterfactual thinking. Psychological Bulletin, 121, 133-148.

Roese, N. J. (1999). Counterfactual thinking and decision making. Psychonomic Bulletin and Review, 6, 570-578.

Roese, N. J. (2000). Counterfactual thinking and marketing. Psychology and Marketing, 17, 277-280.

Roese, N. J. (2005). If only. New York: Broadway Books.

Roese, N. J., Hur, T., \& Pennington, G. L. (1999). Counterfactual thinking and regulatory focus: Implications for action versus inaction and sufficiency versus necessity. Journal of Personality and Social Psychology, $77,1109-1120$.

Roese, N. J., \& Olson, J. M. (1997). Counterfactual thinking: The intersection of affect and function. In M. P. Zanna (Ed.), Advances in experimental social psychology (Vol. 29, pp. 1-59). San Diego, CA: Academic Press.

Roese, N. J., \& Olson, J. M. (in press). Better, stronger, faster: Self-serving judgment, affect regulation, and the optimal vigilance hypothesis. Perspectives on Psychological Science.

Roese, N. J., Pennington, G., Coleman, J., Janicki, M., Li, N., \& Kenrick, D. T. (2006). Sex differences in regret: All for love or some for lust? Personality and Social Psychology Bulletin, 32, 770-780.

Roese, N. J., Sanna, L. J., \& Galinsky, A. D. (2005). The mechanics of imagination: Automaticity and control in counterfactual thinking. In R. R. Hassin, J. S. Uleman, \& J. A. Bargh (Eds.), The new unconscious (pp. 138-170). New York: Oxford University Press.

Roese, N. J., \& Sherman, J. W. (in press). Expectancies. In A. W. Kruglanski \& E. T. Higgins (Eds.), Social psychology: A handbook of basic principles (Vol. 2). New York: Guilford.

Roese, N. J., \& Summerville, A. (2005). What we regret most ... and why. Personality and Social Psychology Bulletin, 31, 1273-1285.

Sabini, J., \& Silver, M. (2005). Why emotion names and experiences don't neatly pair. Psychological Inquiry, 16, 1-10.

Zeelenberg, M., \& Pieters, R. (1999). Comparing service delivery to what might have been: Behavioral responses to regret and disappointment. Journal of Service Research, 2, 86-97.

Zeelenberg, M. \& Pieters, R. (2007). A theory of regret regulation 1.0. Joumal of Consumer Psychology, 17, 3-18. 